\title{
Ambiência inovadora: uma análise da trajetória a partir do radar da inovação no comércio varejista do Rio Grande do Norte
}

\author{
Breakthrough ambience: A look in the path from the innovation's radar in the retail \\ trade of Rio Grande do Norte
}

\author{
${ }^{1}$ Luzia Ligianne de Oliveira e ${ }^{2}$ Napiê Galvê Araújo Silva \\ ${ }^{1}$ Administradora, Especialista em Gestão Estratégica de Negócios pela Universidade Federal do Rio Grande do \\ Norte, Natal, RN, Brasil \\ ligianne.ali@gmail.com \\ ${ }^{2}$ Economista, Mestre em Economia e em Políticas Públicas e Sociedade, Doutorando em Ciências Sociais, \\ Professor Assistente II, UFERSA, Mossoró, RN, Brasil. \\ napiegalve@yahoo.com.br
}

\begin{abstract}
Resumo
Atualmente o cenário nacional é composto por instabilidade e incertezas, e as empresas estão nesse meio, buscadas soluções que as ajude a superar esse momento de dificuldades. Muitas organizações estão encontrando saída na inovação, para realizar o desenvolvimento do negócio sem grandes custos. O Serviço de Apoio às Micro e Pequenas Empresas (SEBRAE) em parceria com o Conselho Nacional de desenvolvimento Cientifico e Tecnológico (CNPq) promove a disseminação do conhecimento de inovação através do Programa Agentes Locais de Inovação (ALI). Diante disso, o presente estudo busca conhecer os avanços realizados em empresas participantes do programa ALI, em relação a ambiência Inovadora e ao nível de Inovação Global da empresa. O trabalho foi desenvolvido a partir de pesquisa Bibliográfica, Descritiva e de Campo. Como resultado foi possível identificar um avanço nos níveis de inovação em todas as empresas, principalmente nas situadas na região Oeste do Estado. Logo, visualiza-se a importância do programa ALI para as empresas participantes, levando em consideração a realização das ações propostas pelos Agentes, que refletiram em resultados positivos.
\end{abstract}

Palavras-chave: Gestão; Inovação; Ambiência Inovadora.

\begin{abstract}
Currently the national scene is composed of instability and uncertainties, and corporations are in that environment, searched solutions that helps them outgrow this moment of difficulty. Many organizations are finding out innovation, to carry out business development with no major costs. The Support Micro and Small Enterprises (Sebrae) in collaboration with the National Council for Scientific and Technological Development $(\mathrm{CNPq})$ promotes the dissemination of knowledge by innovation through Agents Program Innovation Local (ALI). Facing this, the current study aimed to know the achievements of the participants of the ALI program enterprises, in relation to Breakthrough ambience and the level of Global Innovation of company. The study was developed from the Bibliographic, Descriptive and Field research. As a result it was possible to identify an advance in the levels of innovation in all companies, located especially in the the state's Western region. So, we see the importance of the ALI program for participating companies, taking into account the performance of the proposed actions by the Agents, which reflected in positive results.
\end{abstract}

Keywords: Management; Innovation; Breakthrough Ambience. 


\section{Introdução}

A crise que vem se expandindo na economia do mundo inteiro vem forçando empresas a mudarem seus comportamentos e suas atitudes para poderem permanecer estáveis no mercado. Não é obstante o fato de que muitas organizações têm se perdido neste novo ambiente, ambiente de incertezas sobre o futuro dos negócios, desse modo muitos empreendimentos têm entrado em declínio e em muitos casos decretam a sua falência.

O Comercio Varejista é um dos setores da economia que vem entrando em dificuldades, visto que os ajustes econômicos têm contribuído para uma desaceleração desse setor, que no cenário mais otimista culmina no aumento do desemprego e no menos esperado na diminuição dessas empresas. As empresas que tem conseguido atravessar esse momento de turbulência têm encontrado apoio na criatividade, buscando soluções simples, mas com efeitos eficazes. Muitas delas estão aproveitando o momento para capacitar-se e evitar que sejam engolidas por essa onda que eclode no momento.

A inovação cada vez mais vem conquistando seu espaço, dentre muitos empresários, e as ações no campo da Gestão da Inovação tem apresentado destaque nesse cenário. As empresas estão se conscientizando da importância de desenvolver um ambiente propicio para o desenvolvimento da inovação, que na maioria das vezes resulta na redução de despesas ou na possibilidade de aumento da lucratividade do negócio. Com o intuito de conhecer as mudanças realizadas nas empresas através do radar da inovação ${ }^{1}$, o presente trabalho apresenta grande valia no que diz respeito a obtenção de informações sobre uma temática que está em desenvolvimento no país: A Inovação. A partir desse estudo será possível conhecer o desempenho dessa ferramenta nos negócios, visualizando o avanço do mesmo.

O estudo apresentará informações reais sobre o desenvolvimento das micro e pequenas empresas que atuam no estado do Rio Grande do Norte a partir do radar da inovação, ferramenta usada em todo o país, e com isso possibilitará a mensuração de informações importantes sobre o desenvolvimento da inovação nesses empreendimentos. O presente estudo apresentará contribuições importantes para o setor do comercio varejista, visto que mostrará informações sobre a realidade dessas empresas podendo apontar soluções simples e práticas para dificuldades em comum a este segmento.

Também contribuirá como fonte de pesquisa para o meio acadêmico, onde servirá de base para estudos futuros de estudantes e pesquisadores desta área no país, e até mesmo fora dele. O estudo também servirá como medidor do comportamento dessas empresas na busca por conhecimento e com isso sua participação em capacitações, desse modo apresentará ao Serviço de Apoio

1 Ferramenta utilizada pelo Programa ALI para medir o Grau de Inovação nas Empresas às Micro e Pequenas Empresas (SEBRAE) informações importantes sobre o seu público alvo.

Diante do exposto uma questão que pode ser ressaltada é: Houveram mudanças significativas a partir do radar da inovação entre o momento inicial e o momento final do Programa ALI? Para responder a essa problemática o presente estudo tem como objetivo principal "Analisar a trajetória do grau de inovação com enfoque na dimensão Ambiência Inovadora nas empresas do comércio varejista, atendidas pelo programa ALI, realizando uma comparação entre as regiões atendidas". Para atingir tal objetivo será necessário verificar o desempenho do grau de inovação com base no radar da inovação; Realizar levantamento por região (Agreste, Alto Oeste, Oeste, Seridó e Vale do Açu); Mostrar o desenvolvimento da dimensão Ambiência Inovadora e; Expor quais regiões obtiveram melhores resultados

\section{Métodos}

A presente pesquisa compreende o estudo de um determinado grupo de empresas do comércio varejista do Rio Grande do Norte participantes do Programa Agentes Locais de Inovação do Sebrae em parceria com o Conselho Nacional de Desenvolvimento Científico e Tecnológico (CNPq). Constituída por 50 Micro e Pequenas empresas, com faturamento máximo de 3.600.000,00 que estejam situadas nas regiões Agreste, Alto Oeste, Oeste, Seridó e Vale do Açu no estado do Rio Grande do Norte.

Este estudo compreende apresentar a trajetória dessas empresas dentro do programa, ou seja, sua evolução entre as etapas do mesmo, que irá apresentar o cenário que as empresas se encontram e as alterações obtidas no que concerne à inovação entre os seus ciclos, conhecidos como Ciclo 0 - o momento inicial da pesquisa - Ciclo 1 - um segundo momento onde a empresa já implantou algumas ações inovadoras - e Ciclo 2 - o momento final, depois de uma série de ações.

O objetivo maior é poder mensurar o avanço dessas empresas em relação a inovação, através da trajetória percorrida nos diferentes momentos durante os 20 meses de pesquisa direta, podendo acompanhar e verificar as áreas desenvolvidas que causaram impactos significativos para o crescimento da empresa dentro do programa e fazer comparação direta entre as regiões que mais se destacaram no estado. Diante disso esse artigo apresenta característico de estudo descritivo segundo Gil (2008, p.28) quando afirma que "as pesquisas descritivas têm como objetivo primordial a descrição das características de determinada população ou fenômeno ou o estabelecimento de relações entre variáveis"

Já a abordagem desse estudo compreende a abordagem Quantitativa tendo como foco no estudo e descrição de determinadas informações. O campo de observação desse estudo é o comércio varejista de vestuário e acessórios do Rio Grande do Norte, tendo como amostra o 
Tabela 1 - Definição das dimensões da inovação

\begin{tabular}{|c|c|}
\hline DIMENSÃO & DEFINIÇÃO \\
\hline Oferta & Desenvolvimento de produtos com características inovadoras. \\
\hline Processos & $\begin{array}{c}\text { Redesenho dos processos produtivos de modo a permitir incremento de eficiência } \\
\text { operacional. }\end{array}$ \\
\hline Clientes & Identificar necessidades dos clientes, ou novos nichos de mercado. \\
\hline Praça & Identificar novas formas de comercialização e/ou distribuição. \\
\hline Plataforma & $\begin{array}{l}\text { Relaciona-se com a adaptabilidade do sistema de produção face à diversidade de } \\
\text { produtos demandados. }\end{array}$ \\
\hline Marca & Forma como as empresas transmitem aos clientes seus valores. \\
\hline Soluções & Sistemas ou mecanismos para simplificar as dificuldades do cliente. \\
\hline Relacionamento & Relaciona-se com a experiência do cliente com a empresa. \\
\hline Agregação de valor & $\begin{array}{c}\text { Melhorar a forma de captar o valor dos produtos percebido por cliente e } \\
\text { fornecedores. }\end{array}$ \\
\hline Organização & Melhorar a estrutura da empresa. \\
\hline Cadeia de fornecimento & Incrementar a logística com os fornecedores e clientes, sejam internos ou externos. \\
\hline Rede & Comunicação entre os elos da cadeia de fornecimento. \\
\hline Ambiência Inovadora & $\begin{array}{l}\text { Relaciona-se com os profissionais que compõem a empresa e que colaboram com } \\
\text { a cultura da inovação }\end{array}$ \\
\hline
\end{tabular}

Fonte: Sawhney et al. (2006 e 2010) e Bachmann e Destefani (2008).

número de 50 empresas situadas nas Regiões: Agreste, Alto Oeste, Oeste, Seridó e Vale do Açu. O Instrumento de pesquisa adotado é o Radar da Inovação através da realização de um diagnóstico realizado na empresa com o proprietário do negócio. A coleta será realizada mediante questionário Estruturado com questões de múltipla escolha.

Para melhor compreensão do Radar da Inovação apresenta-se a Tabela 1, onde são apresentadas as dimensões da inovação propostas por Sawhney, Wolcott e Arroniz (2006) e complementada por Bachmann e Destefani (2008), seguidas de uma breve definição de cada dimensão. A análise desses dados e compilação das informações foi feita conforme a obtenção dos dados da pesquisa, gráficos e tabelas.

\section{Resultados e discursões}

Conforme os procedimentos metodológicos desse estudo foram analisadas cinquenta (50) empresas do comércio varejista de vestuário e acessórios do estado do Rio Grande do Norte, distribuídos nas regiões do Alto Oeste, Oeste, Vale do Açu, Seridó e Agreste. Devido a inacessibilidade das informações, neste estudo não serão apresentados resultados referentes a capital do estado, Natal.

Cada região descrita nesse estudo apresentou uma amostra de 10 empresas, onde foi possível visualizar o grau de inovação da dimensão Ambiência Inovadora e o Grau geral de todas as dimensões juntas, a partir da aplicação do diagnóstico Radar da Inovação aplicada pelos Agentes Locais de Inovação de cada região, e que realizam um trabalho de acompanhamento com as mesmas.

\section{Ambiência Inovadora}

Retomando a revisão bibliográfica desse estudo pode-se concluir que a dimensão Ambiência Inovadora trata da criação de um ambiente aberto a ideias inovadoras, que pode ser criado levando em consideração algumas ações realizadas pela empresa Batchmann (2008).Como por exemplo a participação em palestras e cursos, absorção de algum tipo de tecnologia, a busca por informações em seminários e congressos, Aquisição de informações técnicas como patentes, abando de algum projeto desenvolvido, e obtenção de programas de apoio do governo e se a empresa dispõe de algum sistema para colher informações dos colaboradores. O Diagnóstico radar da inovação se baseia em todos esses pontos para gerar o grau de inovação de determinada empresa neste quesito.

Ainda de acordo com esse autor existem várias formas de avaliar o ambiente propicio a inovação que uma organização apresenta uma delas "é medir a fração inovação da equipe que é composta por profissionais que tem formação voltada para a pesquisa" Batchmann (2008). Entretanto o autor reconhece que a presença de profissionais com esse enfoque ainda é incomum na 


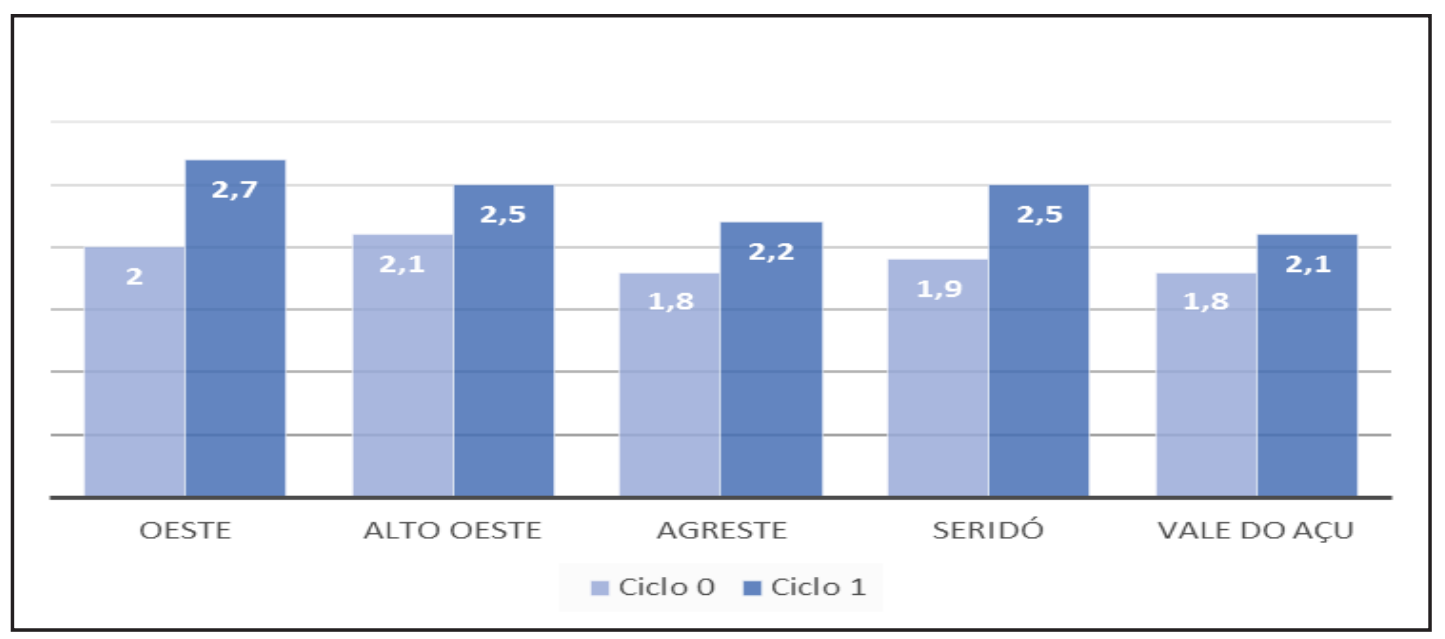

Gráfico 1 - Avanço entre os ciclos da Ambiência Inovadora: resultados por região

realidade das MPE's.

O autor também acredita que outro aspecto importante para a mensuração da ambiência inovadora seja a existência de mecanismo e ferramentas como programas de sugestões que estimulem os colaboradores a apresentarem ideias. Isso vai de encontro às observações de Mattar (2011) que acredita que a gestão de ideias compreende um ponto fundamental para o desenvolvimento e gerenciamento de ações inovadoras nas organizações contemporâneas.

Diante disso e com base nas informações colhidas nessa pesquisa foi possível perceber que as empresas de vestuário e acessórios do estado do Rio Grande do Norte apresentam uma média de 2,1 nesta dimensão, considerando os dois ciclos observados (Ciclo 0 e Ciclo 1). Cada Ciclo compreende o registro de como está a empresa em um determinado momento. $\mathrm{O}$ ciclo 0 referese ao ponto inicial, o momento em que o agente teve o primeiro contato com a empresa e realizou o diagnóstico para identificar a real situação e propor um plano de ação que possa desenvolver a dimensão. O ciclo 1 refere-se a um período de tempo depois, geralmente de 8 meses (podendo variar), onde algumas ações já foram realizadas na empresa, e com isso registra-se o momento para saber se houve avanço e qual a intensidade.

Diante disso se faz necessário observar se houve algum avanço na trajetória dessas empresas na referida dimensão. Esse avanço consiste na realização de ações que aumentem a pontuação das empresas nesse quesito, mostrando que a empresa tentou desenvolver um ambiente mais propicio a ações inovadoras. Partindo dessa premissa tem-se os seguintes resultados:

O quesito Ambiência Inovadora apresentou resultados positivos de acordo com a radar da inovação, visto que, em todas as empresas houve um aumento do grau de inovação dessa dimensão do ciclo 0 para o ciclo 1 , o que quer dizer que ocorreram mudanças nessas organizações, e que as ações propostas pelos agentes apresentaram bons resultados.
As médias de cada região estão detalhadas no Gráfico 1. Dentre as regiões analisadas a que apresentou maior avanço foram as empresas da região Oeste que partiram da pontuação 2 no ciclo 0 para 2,7 no ciclo 1 , isso ocorreu principalmente devido a participação dessas empresas em palestras, cursos de gestão, congressos e feiras na área em que elas atuam.

Em seguida estão dispostas as outras regiões que também apresentaram progresso, mas em menor escala. As empresas situadas nas regiões do Seridó com avanço de 1,9 para 2,5, Agreste com 1,8 até 2,2, Alto Oeste com 2,1 a 2,5 e por fim o Vale do Açu com 1,8 a 2.1.

Dentre os pontos que a dimensão Ambiência Inovadora contempla alguns apresentaram pouca representatividade, como por exemplo o uso sistemático de informações técnicas, pagando taxas ou royalties por invenções patenteadas, ou até mesmo a realização de projetos para desenvolver novos produtos, processos, modo de trabalho etc.

Aqui não cabe avaliar porque esses aspectos apresentam baixa expressividade, mas esse pode ser um ponto interessante para impulsionar outros estudos nesta área.

Todas essas informações estão dispostas no gráfico 1 .

\section{Grau de Inovação Global}

É importante entender o que compreende o Grau de Inovação Global contido no Radar da Inovação. Este representa o resultado obtido através da média de todas as outras dimensões, em outras palavras pode ser traduzida como a média obtida com a soma das dimensões Oferta, Plataforma, Marca, Clientes, Soluções, Relacionamento, Agregação de valor, Processos, Organização, Cadeia de fornecimento, Presença, Rede e por fim Ambiência Inovadora.

Vale salientar o entendimento por inovação adotado nessa pesquisa que em seu sentido mais amplo o Manual de Oslo (2005) define como sendo a criação de um produto/serviço novo, ou significativamente melhorado. 


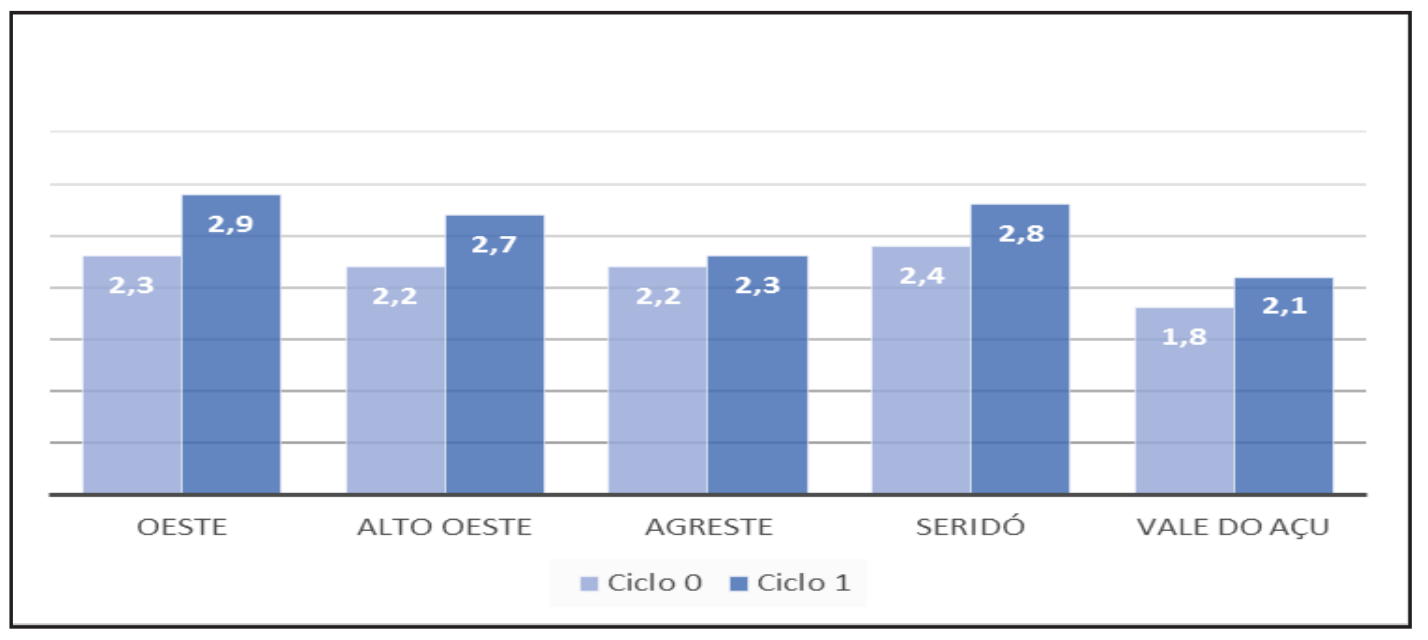

Gráfico 2 - Progresso do Grau de Inovação Global: resultados por região

Ainda amplia o conceito mostrando que o "novo" não precisa ser necessariamente um produto ou serviço, como também pode acontecer nos processos, no marketing ou no campo organizacional da empresa. Já Drucker (1987) adiciona ao conceito exposto no Manual o fator riqueza no que concerne à inovação. Para ele a inovação consiste na habilidade de transformar algo que já existe em um recurso que gere valor ou riqueza. O referido Autor vai além quando defende que a inovação não precisa necessariamente ser técnica ou até mesmo uma "coisa", ele valida sua afirmativa citando o exemplo da compra à prestação que segundo ele foi uma inovação que exigiu apenas uma ideia e que revolucionou o mercado mundial.

A partir disso têm-se os seguintes resultados:

Todas as empresas analisadas no estado do Rio Grande do Norte apresentaram avanço na sua trajetória dentro do programa ALI, trajetória essa que compreende os ciclos 0 e 1 descritos anteriormente. Isso reflete a realização das ações propostas pelos Agentes Locais de Inovação que atendem essas empresas.

Esse progresso descrito no parágrafo anterior expõe a realização de algumas ações que contribuíram para o desenvolvimento do Grau de Inovação Global. Vale salientar que algumas dimensões não apresentaram mudanças significativas, enquanto outras podem ter regredido (Isso devido a fatores externos a empresa). $\mathrm{O}$ fato é que o número de dimensões que avançaram foi maior do que as que regrediram, por isso pode-se concluir que as ações propostas pelos agentes foram positivas.

Dentre as regiões estudadas, como aconteceu na dimensão ambiência Inovadora, mais uma veza região com maior avanço foi a região Oeste com diferença significativa entre o Ciclo 0 e 1 . No primeiro registro as empresas situadas nessa região apresentaram pontuação de 2,3 e no segundo momento de registro que equivale ao ciclo 1 as empresas apresentaram score de 2.9, o maior registrado entre empresas do comércio de vestuário e acessórios que foram analisadas no estado.

Em seguida vem a região do Alto Oeste que apre- sentou em seu ciclo 0 a pontuação de 2,2 e no ciclo 1 foi registrado uma média de 2,7. Em seguida está à região do Seridó, que apesar de ter a segunda media mais alta apresentou avanço um pouco abaixo da região anterior. O Seridó apresentou score de 2,4 no ciclo 0 e de 2,8 no ciclo 1.

Levando em consideração o avanço obtido nessas regiões, ou seja, o aumento entre o ciclo 0 e o ciclo 1 do Programa ALI tem-se a região do Vale do Açu e do Agreste, com avanço de 1,8 para 2,1 e 2,2 para 2,3 respectivamente.

É importante salientar que para fins de análise, nesse estudo observa-se o progresso com base nas alterações entre os números de um ciclo e outro, ou seja, o registro de um determinado momento e o registro de outro posterior. As informações descritas nessa secção estão dispostas no gráfico 2 .

\section{Conclusões}

Várias foram as mudanças ocorridas nessa última década, desde os aspectos econômicos aos aspectos relacionados aos hábitos pessoais dos indivíduos, e neste meio também estão inseridas as empresas. Muitas foram às dificuldades e maior que isso foi o aprendizado e a experiência adquirida com todas as adversidades. O programa ALI veio a alguns anos trabalhando no fomento a gestão e a inovação das Micro e Pequenas Empresas de todo o Brasil inclusive do estado do Rio Grande do Norte. E aqui, começamos a visualizar os primeiros frutos de um trabalho realizado em parceria com o SEBRAE e as empresas.

Com o intuito de conhecer a trajetória das empresas em relação a dimensão ambiência inovadora, tão importante por ser a porta de entrada para um espaço de inovações dentro das empresas, o presente estudo atingiu seu principal objetivo, mostrando não somente a simples trajetória dessas empresas, mas principalmente 
que nessa trajetória houveram avanços e que as ações propostas em um primeiro momento, apresentaram resultados em temos numéricos em outro momento. Também foi possível identificar a realização de progressos na trajetória das empresas não somente na dimensão ambiência inovadora, mas principalmente na média obtida com a soma de todas as outras dimensões. O que permite concluir que muitos aspectos levantados pelo radar também apresentaram resultados positivos, e que as ações propostas pelos Agentes Locais de fato apresentaram impactos nas organizações.

A partir dessas analises foi possível realizar um levantamento de informações por regiões e verificar qual região do estado apresentou resultados mais significativos e quais apresentaram índices inferiores. Essa é uma informação importante, visto que, a gestão do programa pode a partir dessas informações planejarem estratégias para impulsionar as regiões com menos expressividade.

Das informações colhidas visualizou-se que a região Oeste do Estado apresentou os melhores resultados tanto em relação à dimensão Ambiência Inovadora como no Grau de Inovação Global, lembrando que aqui é definido pelo avanço entre os ciclos 0 e 1 . Diante das informações apresentadas nessa pesquisa é possível visualizar a importância do programa ALI para essas empresas, levando em consideração que o mesmo não realiza somente um diagnóstico da atual situação da empresa, vai, além disso, propõe um plano de ação, que quando seguido, apresenta resultados positivos. Esses resultados vão além dos números apresentados nessa pesquisa, mas sim, culmina no desenvolvimento do negócio em questão.

\section{Referências}

BACHMANN \& ASSOCIADOS. Metodologia para estimar o grau de inovação nas MPE. Curitiba: 2008

BACHMANN, Dórian. L.; DESTEFANI, Jully Heverly. Metodologia para estimar o grau de inovação nas MPE. XVIII Seminário Nacional de Parques Tecnológicos e Incubadoras de Empresas. Aracaju, 2008.

DRUKER, Peter Ferdinand. Inovação e espírito empreendedor. Editora Pioneira, 1987.

GIL, A. C. Métodos e técnicas de pesquisa social. 6. ed. São Paulo: Atlas, 2008. p. 200.

MATTAR, Fauze Najib. Administração de Varejo. Rio de Janeiro: Elsevier, 2011.

OCDE. Manual de Oslo - Diretrizes para a coleta e interpretação de dados sobre Inovação. $3^{\mathrm{a}}$ ed., Tradução FINEP, 2005, Disponível em: http://www.finep.gov.br Acesso em 29 Jul. 2014
SAWHNEY, M.; WOLCOTT, R. C.; ARRONIZ, I.. The 12 DifferentWays for CompaniestoInnovate. MIT Sloan Management Review, v.47, n.3, p.75-81, 2006.

SAWHNEY, M.; CHEN, J..Definingandmeasuring business innovation: theinnovation radar. MIT Sloan Management Review, 1611264, 2010. 